\title{
LITERATURA Y PRENSA DE LA INDEPENDENCIA, INDEPENDENCIA DE LA LITERATURA
}

\author{
Bernardo Subercaseaux \\ Universidad de Chile \\ besuberc@uchile.cl
}

RESUMEN/ ABSTRACT

El artículo examina las concepciones operantes del libro, la lectura y la literatura en Chile, entre 1810 y 1842 . Describe la concepción enciclópedica y eminentemente política de lo literario en las dos primeras generaciones de criollos ilustrados y el modo como ella fue conformando un canon para la nueva nación. Contrasta luego el discurso de la utopía ilustrada (entendida como "verdad prematura") sobre la lectura y el libro con testimonios sobre su realidad. Finalmente enfrenta ambas perspectivas y las vincula a la independencia de la literatura.

Palabras Clave: ilustración, republicanismo, lectura, libro, prensa, independencia, canon, testimonio, tiempo fundacional.

The article examines the perception about books, reading and literature in Chile, between 1810 and 1842. It deals with the vision of the two first generations of intellectuals about this subject, a vision politically motivated. It then goes on to establish a constrast between the utopical vision and the real experience in the area of book and reading. The article finally confronts both visions in relation to the independence of literature.

KEY WORDS: enlightment, republicanism, reading, book, printing press, independence, canon, testimony, foundational time.

Los letrados criollos que después de la Independencia se ocupan del tema del libro y la lectura en función del nuevo orden de la nación, pertenecen, básicamente, a la generaciones de 1810 y a la de 1842, generación ésta última 
que se percibe a sí misma -a pesar del interregno de casi 30 años- como continuadora y depositaria de la anterior. Las figuras más destacadas de la primera son Camilo Henríquez (1769-1825), Manuel de Salas (1754-1841) y Juan Egaña (1768-1836) y de la segunda, José Victorino Lastarria (18171888), Francisco Bilbao (1823-1865), algunos exiliados argentinos como Sarmiento, y discípulos de los anteriores que empiezan a participar en la vida pública a fines del decenio de Bulnes, como Benjamín Vicuña Mackenna (1831-1886). Todos ellos conforman una comunidad de lectores en la medida en que comparten códigos, valores, supuestos e ideales, lo que incide en sus prácticas lectoras y en la valoración de ciertos autores o de uno u otro título, preferencias que se manifiestan en el periodismo de ideas posterior a la Independencia.

¿Cuáles son, entonces, las características que comparten estas figuras, y que nos permiten hablar de prácticas lectoras compartidas o -siguiendo a Roger Chartier- de una comunidad de interpretación que a partir de ciertos códigos va a perfilar el espacio público de la época? ${ }^{1}$

Todos son intelectuales polifacéticos al estilo decimonónico, que asumen la ilustración desde una racionalidad militante y que conciben a los fundamentos filosófico-políticos de las "luces" como la base de su pensamiento y de su acción, a la razón como instancia ordenadora del conocimiento, a la libertad como valor supremo y a la república como la forma de gobierno más adecuada para la nueva nación. Son letrados que participan del optimismo histórico y de la idea del progreso indefinido, que perciben a la educación como el instrumento para formar ciudadanos, y a la cultura letrada como el ámbito para esa formación. Todos ellos vivieron persecución y exilio por sus ideas. Camilo Henríquez en 1809 fue visitado por la Inquisición en su celda limeña de Fraile de la Orden de la Buena Muerte, y como se relata en los Anales de la Inquisición, en la primera visita, tras registrar muebles y estantes, el inquisidor se retiró luego de no encontrar nada. El denunciante, sin embargo, que era un fraile dominico, insistió, y la Inquisición dispuso nueva pesquisa, encontrando esta vez en el interior del colchón algunos libros prohibidos, entre otros, de Rousseau y Voltaire ${ }^{2}$. Como consecuencia de esa segunda visita, Camilo Henríquez fue conducido a un calabozo del Santo Oficio. Ocultar esos libros en su cama, era ya, una forma temprana de incluirlos en el canon,

1 Véase Chartier, una de las ideas matrices en El mundo como representación.

2 Véase Palma 86. 
de escoger lo que había que leer. Después del desastre de Rancagua, Camilo Henríquez se exilió en Argentina. También fueron perseguidos y desterrados por sus ideas, en algún punto de su trayectoria, Juan Egaña, Manuel de Salas, Lastarria, Bilbao, Sarmiento y Vicuña Mackenna.

Todos ellos tenían una concepción enciclopédica y no restrictiva de lo literario, que iba mucho más allá de lo que entonces se entendía por las "bellas letras". Literatura era no solo la expresión imaginaria, sino toda expresión escrita, y aún más, toda actividad letrada que tuviese un fin edificante, que apuntara a transformar los residuos de la mentalidad colonial en virtudes cívicas y en una nueva conciencia nacional. Camilo Henríquez hablaba de "escritos luminosos para la suerte de la humanidad", englobando en este concepto a los libros de imaginación y a los de pensamiento, "feliz el pueblo" -escribía en La Aurora de 1812- que tiene poetas, "a los poetas seguirán los filósofos, a los filósofos los políticos profundos”, y son sobre todo estos escritos de pensamiento (cuyo retraso se debía a la pereza de la razón) los que alcanzan para Camilo Henríquez un rango superior, se trata, decía, de "la sublime ciencia de hacer felices a las naciones". De allí que cuando, en 1812, refiriéndose al arribo desde Estados Unidos de la primera y muy rudimentaria imprenta que se instala en el país, Camilo Henríquez la bautizó como "la máquina de la felicidad". Imprenta que años más tarde, durante la Reconquista, sería rebautizada por los realistas como "la máquina de las mentiras", convirtiendo a los patriotas ilustrados o "sabios" que la usaban, en "revoltosos", "caudillos" y "tiranos", y a sus escritos en "papeles sediciosos" que propiciaban "conductas delincuentes" 3 .

Tres décadas más tarde, Lastarria, en el Discurso inaugural de la Sociedad Literaria de 1842, reafirmando, la concepción enciclopédica de la literatura, señalaba que "entre sus cuantiosos materiales", ésta incluye "las concepciones elevadas del filósofo y del jurista, las verdades irrecusables del historiador, los desahogos de la correspondencia familiar" y por último "los raptos y los éxtasis deliciosos del poeta". De hecho, al revisar las actas de la Sociedad, llama la atención la variedad de materias que se tratan en las sesiones. Francisco Bilbao lee un trabajo sobre sicología y soberanía popular; Juan, hijo de Andrés Bello, lee una obra de teatro y una descripción geográfica de Egipto; Santiago Lindsay recita poemas patrióticos, otro joven

\footnotetext{
3 Expresiones que se encuentran en documentos realistas del período 1814-1817 y en Martínez 14.
} 
diserta sobre el espíritu feudal y aristocrático, y varias sesiones se dedican al análisis de las cualidades que debería tener un libro para la instrucción general del pueblo.

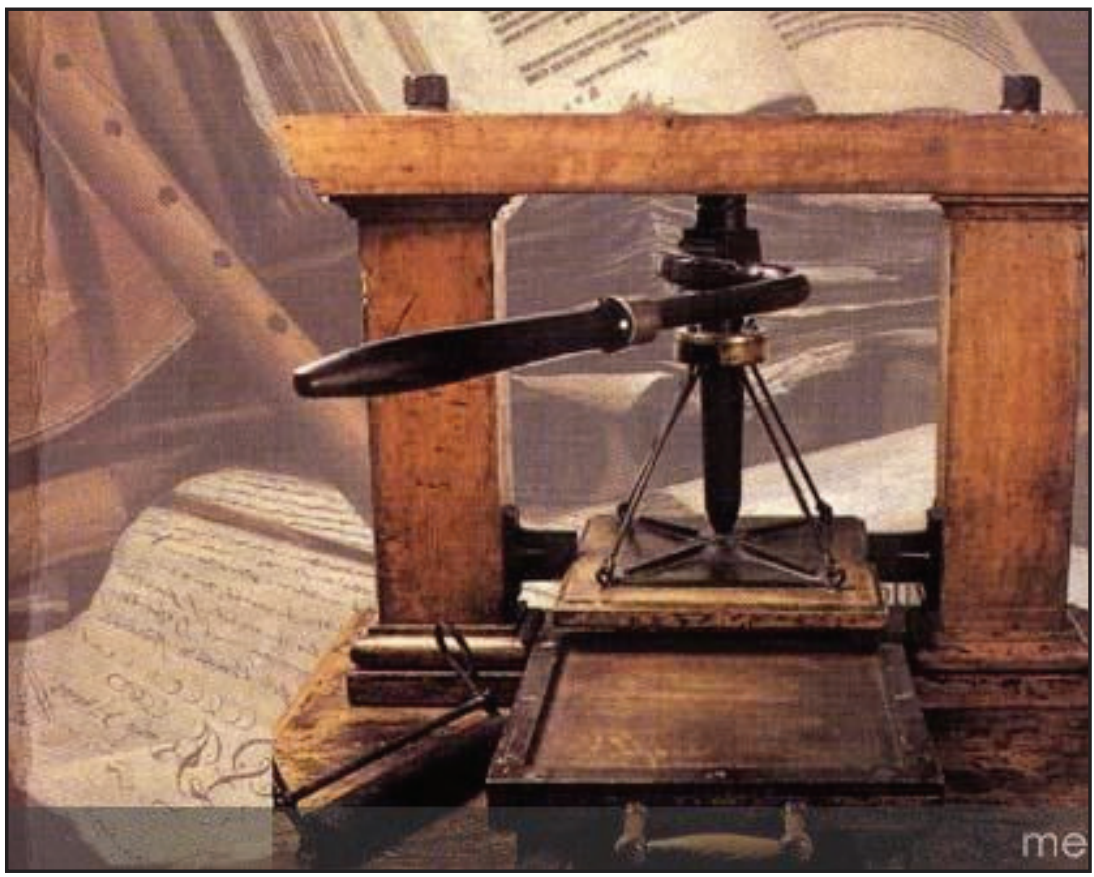

La máquina de la felicidad

Otro rasgo que comparten estos autores es la seriedad y solemnidad con que acometen la tarea intelectual. En la Aurora de Chile, primer periódico que se editó en el país, y que dirigido por Camilo Henríquez publicó entre 1812 y 1813 un total de 62 ediciones, no hay ni un solo rasgo de humor ni siquiera un guiño, el lenguaje es siempre solemne, formal, sentencioso, inflamado y grave. Por su parte, en la Sociedad Literaria de 1842 llama la atención la normatividad estricta de las sesiones. Está -según consignan las actas- expresamente prohibido fumar, ningún miembro puede salir a la calle durante las reuniones; hay -por reglamento- un fiscal que debe controlar la asistencia y sentarse siempre -también por reglamento- al lado izquierdo del Director. 

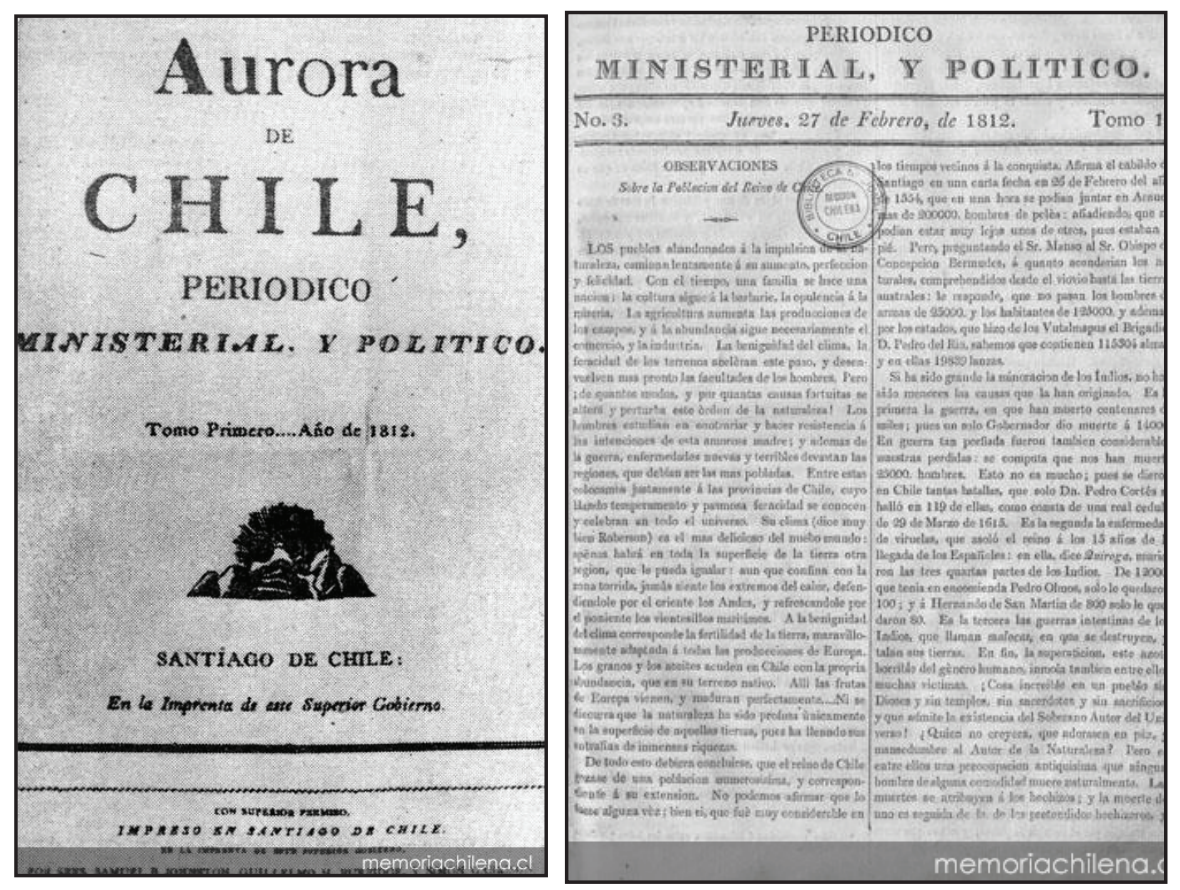

La Aurora de Chile. Periódico ministerial y político. El primer periódico nacional

Las actas hacen pensar, más que en jóvenes románticos, en déspotas ilustrados. Los rasgos de solemnidad revelan, por encima de lo anecdótico, tanto en Camilo Henríquez como en los jóvenes de 1842, una determinada conciencia histórica. Se autoperciben como artífices y cruzados en las batallas de la Independencia (los primeros) y de la Civilización (los segundos). El hálito fundacional y la voluntad de construcción no dejan resquicios para el humor ni siquiera en la lectura: Francisco Bilbao afirmaba muy orondo que el Quijote no había conseguido hacerlo reír ni una sola vez. No hay espacio ni para el irracionalismo, ni para el vuelco emotivo personal. Y, si hay emotividad, esta es colectiva, y se manifiesta en la actitud mesiánica y voluntarista con que perciben la tarea de educar el espíritu para modificar la sociedad. Vicuña Mackenna, en sus crónicas, recuerda a Bilbao en una calle barrosa presidiendo a un grupo de jóvenes en procesión, llevando, como iluminado, un árbol de la libertad hecho de mostacillas. 
Son antecedentes que revelan una vivencia compartida y una escenificación colectiva del tiempo histórico nacional. Hablamos de escenificación porque esta vivencia implica una teatralización del tiempo histórico y de la memoria común. Escenificar el tiempo, en el sentido de que se establecen relaciones de anterioridad (con un "ayer" que se perfila como un lastre, como un pasado que hay que dejar atrás y superar); relaciones de simultaneidad (con un "hoy" o presente, desde cuyo ángulo se adopta un punto de vista) y relaciones de posterioridad (con un "mañana" de connotaciones teleológicas, constructivistas o utópicas). Desde una escenificación de la temporalidad se establece un relato, o un metarrelato, una narración y códigos compartidos que implican y animan toda índole de discursos. En el caso de las figuras que hemos mencionado se trata de una vivencia colectiva del tiempo histórico en clave de fundación, de una concepción profana del tiempo. Es el tiempo del nacimiento de la nación, del corte con un "antes", un tiempo que perfila un "ayer" hispánico y un ancien régime que se rechaza y que se considera como residuo de un pasado al que cabe borrar o cuando menos, "regenerar". Frente a ese "ayer" se alza un "hoy" que exige emanciparse de ese mundo tronchado, en función de un "mañana" que gracias a la educación, a las virtudes cívicas, a la libertad y al progreso, está llamado a ser-como se decía entonces- "luminoso y feliz". Corresponde a un ideario republicano y liberal que a comienzos del siglo diecinueve representaba una dirección cultural minoritaria, cuyo agente era la elite letrada criolla. Se trata en el momento de la Independencia de una utopía que responde a una concepción de la historia, pero de una utopía que en el momento de la Independencia puede considerarse como una "verdad prematura", puesto que en el curso del siglo esa dirección cultural irá paulatinamente convirtiéndose en hegemónica -en función de los intereses de la elite (pero beneficiando también a capas medias)-, proyectándose con extraordinaria vehemencia a través de diarios, revistas, historiografía, tratados de jurisprudencia, discursos políticos, logias masónicas, clubes de reformas, novelas, piezas de teatro, estado docente y hasta moda y actitudes vitales. Como señala Giorgio Agamben "cada concepción de la historia va siempre acompañada por una determinada experiencia del tiempo que está implícita en ella, y que la condiciona. Del mismo modo, cada cultura es ante todo una determinada experiencia del tiempo y no es posible una nueva cultura sin una modificación de esa experiencia" (19). Vivencias temporales distintas articulan distintos sistemas de representación, también modos distintos de representar, memorizar y conservar el pasado. 
La paulatina hegemonía que esta constelación va a ejercer sobre la elite y la sociedad chilena, y su tensión con la visión ultramontana y conservadora (que se afincó en el peso de la noche y en el sustrato hispano católico) dominan casi todo el espacio intelectual visible del siglo XIX y muy especialmente hasta 1880. Las figuras ilustradas que hemos mencionado son -con sus luces y sus sombras- la base de este edificio.

El pensamiento de Camilo Henríquez, de Manuel de Salas, de Juan Egaña, en fin, de todos los que participaron en la Independencia, está permeado -con matices de diferencia- por esta escenificación del tiempo fundacional. También lo está el pensamiento de la generación de 1842, de Lastarria, de Vicuña Mackenna y otros. No es casual que las primeras publicaciones periódicas del Chile independiente utilicen casi siempre títulos como "La Aurora", "El despertar" o "El crepúsculo", o que la mayoría de los escritos de estos autores recurran con frecuencia a dos sistemas metafóricos o analógicos de hálito fundacional: el lumínico y el vegetal. Los escritos de prensa y ensayos que Camilo Henríquez califica de "luminosos", son escritos que están plagados de "rayos", "chispas", "relámpagos", "aurora" "luz", "oscuridad", "resplandecer" y "porvenir brillante"; se trata de un campo metafórico en que el sol y la luz - que vivifican lo lumínico- simbolizan la libertad y la razón, escenificando un "ayer" oscuro. Por otra parte, la larga serie de sustantivos, verbos y adjetivos del repertorio metafórico vegetal a los que se recurre ("semilla", "raíces", "tronco", "plantar", "crecer", "sembrar", "florecer", "cultivar", "follaje", "brotes", "botón", "ramas", "flores", frutos", etc....) obedece a una concepción teleológica del decurso histórico y del progreso. La humanidad, entonces, es percibida con la metáfora del árbol, de un árbol que podrá -con la independencia y la libertad- desarrollarse hasta la plenitud de sus posibilidades: hasta dar "frutos". Se busca, en todos los órdenes, escenificar un tiempo nuevo, reinventar una identidad nacional alejada del pasado español. Desde esta perspectiva, la historia intelectual del siglo XIX pone en discusión afirmaciones de autores como Luis Mizón, quien señala que "la mentalidad autoritaria, herencia colonial de la ilustración católica, regalista con influencia galicana y utilitaria, es más importante en la Independencia y en todo el siglo XIX que el enciclopedismo ateo" (32).

En un país recién creado, con un índice de analfabetismo que probablemente llegaba al $90 \%$ y con la herencia de una educación colonial escasa y pobre, se trata de una elite intelectual masculina que en una sociedad periférica, como lo era Chile, es la que asume la responsabilidad de formular una ideología de reemplazo ante lo que aparece como desintegración del viejo 
orden. Es la encargada de forjar una autoimagen y una conciencia cívica y nacional que solidifique el nuevo orden. Son figuras que en la constitución de la modernidad ejercen por lo tanto una doble mediación. Por una parte son mediadores de las ideas y los valores ilustrados provenientes de Europa, que se trasladan a la periferia; pero, por otra, son también mediadores entre la élite local y la sociedad tradicional, a la que se proponen transformar e incorporar paulatinamente a la cultura letrada (Serrano 165). Se trata, en definitiva de los primeros intelectuales modernos, a la Voltaire, que ejercen su oficio con vocación de lo público, intelectuales que tienen algo de agitadores políticos, bastante de profetas y no poco de directores espirituales (Savater 370$)^{4}$.

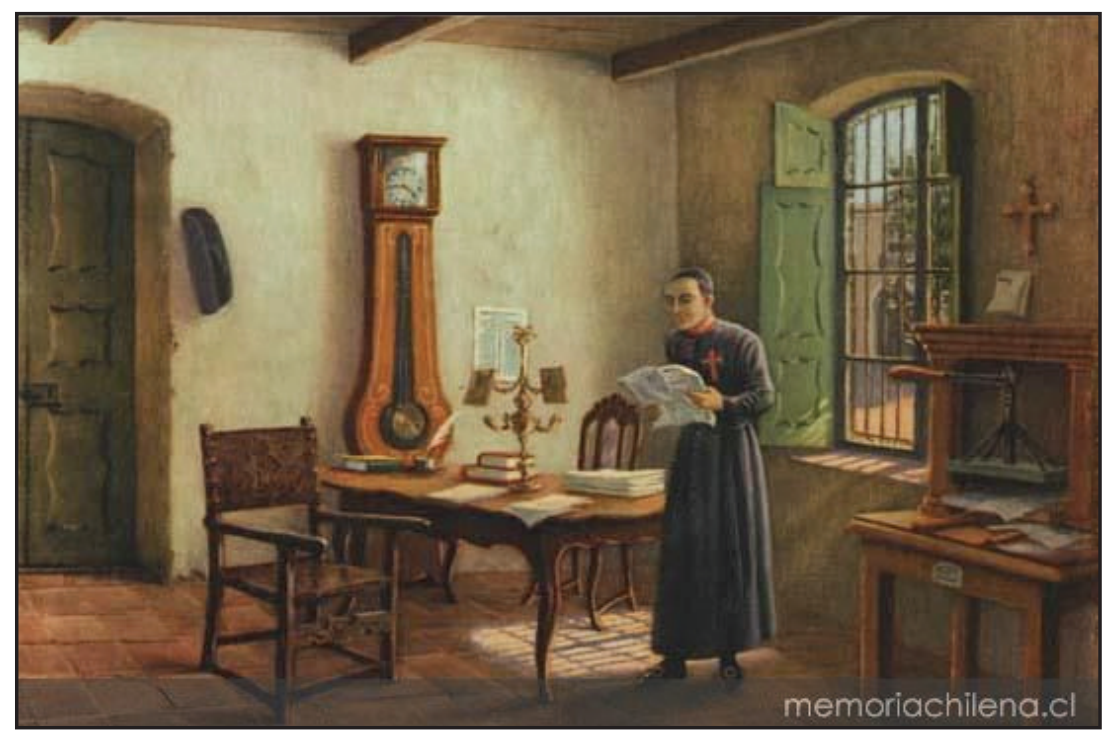

Camilo Henríquez revisa el primer ejemplar de la Aurora de Chile, 1812

Tales son los ideales y supuestos que rigen a la comunidad de lectores que hemos perfilado. La lectura en ellos no es, por lo tanto, una operación abstracta ni la mera intelección de un texto (Chartier, El orden 29), sino que es la puesta en marcha de una mentalidad previa, de un horizonte de expectativas

4 Fernando Savater en su Diccionario Filosófico (1999), señala que Voltaire inaugura la figura del intelectual moderno. 
que interactúa con el texto. En esa interacción se pone en juego un código ideológico cultural en el que están imbricados una concepción de la historia y una vivencia del tiempo. Se trata de preconcepciones compartidas que nos permiten conjeturar lo que tenían en la mente los letrados criollos, conjeturar también desde qué horizonte imaginario interpretaban, elegían o sugerían lo que les interesaba que se leyera, recomendaciones que fueron constituyendo así el canon de la literatura de la Independencia. Podríamos afirmar incluso que las dos generaciones mencionadas inauguran una tradición de lectura con una óptica laica, republicana y liberal, imbuida de una concepción edificante de la lectura en pro del ejercicio ciudadano y de la construcción de la República. Una tradición que tiene como sujeto histórico a la elite criolla letrada (masculina) del siglo XIX, elite que ejercerá un control de lo que se lee, por lo menos durante la primera mitad del siglo, hasta que entra en acción un nuevo público lector de folletines y novelas tardo románticas (mayoritariamente un público femenino), vale decir, hasta que se hace presente un sistema paralelo que responde no a la elite sino que al mercado (Poblete 84).

Se trata de una tradición de lectura que se hace patente en las actas de la Sociedad Literaria de 1842: en algunas sesiones de estudio se leía en voz alta y se comentaba la Historia del Mundo Antiguo de Segur, la de la Edad Media y Moderna de Fleury, y, según destacan las actas, "a Herder cuando resulte conveniente". ¿Pero cuál es el parámetro - preguntamos nosotros-para decidir cuándo resulta conveniente? Estudian a estos autores, como también a Vico -por intermedio de Michelet-y a Herder, haciendo un esfuerzo por establecer una forma de vida nacional; los analizan y estudian con una óptica específica: chilecéntricamente. Jacinto Chacón, uno de los secretarios de la Sociedad que preside Lastarria, escribe un largo poema que divide en tres partes: La Europa, La América y Chile, un poema que titula significativamente: Historia moderna. El poema desarrolla la idea del progreso indefinido y su traslado en tiempo y espacio, desde Europa a América, para asentarse finalmente en Chile. Para los jóvenes de la Sociedad Literaria de 1842, los carriles de la historia desembocan en el país; en una nación que con la Independencia, la Soberanía, la Libertad y los "escritos luminosos" se ubicará en la senda de un país sabio y feliz. Leen e interpretan como si la historia fuese un lago y el pasado ondas concéntricas que se concitan en un punto central, que es la nueva nación. Puede afirmarse, entonces, que la conciencia ilustrada en sus vertientes republicana y liberal es abstractamente nacionalista, puesto que en su intento fundacional se define casi en la pura oposición a lo español y 
al pasado colonial. Se trata, en una primera etapa, de construir una identidad por negación. "Lo chileno" para estos lectores nace, entonces, como valor y como idea antes de tener una existencia real. Es precisamente esta óptica la que explica la preeminencia de una literatura de ideas y de emancipación por sobre una literatura de imaginación, con fines propiamente estéticos. A ello se debe también un imaginario de la Independencia como corte histórico tajante, y no como la continuidad de una modernización que ya en alguna medida se había iniciado a fines de la Colonia con las reformas borbónicas ${ }^{5}$.

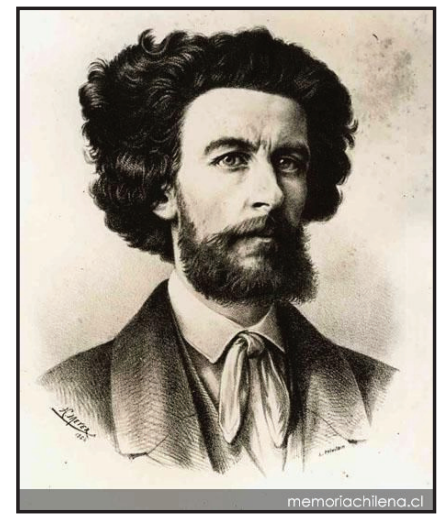

Francisco Bilbao

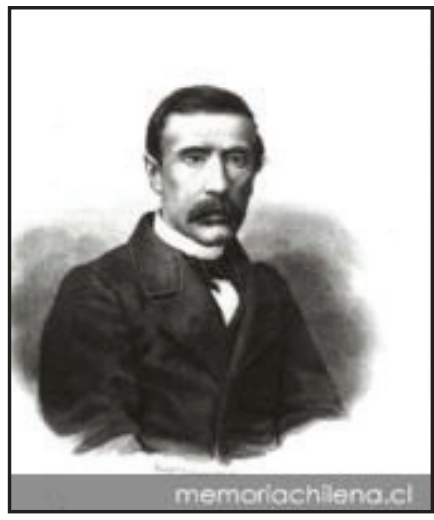

José Victorino Lastarria

Desde esa mentalidad lectora se irá estableciendo el canon de autores y títulos necesarios, mentalidad que alimentó a la prensa de ideas de la época y que opera ya en 1812 y 1813 , en los 62 números de la Aurora. Periódico del que su editor y redactor principal y casi único fue Camilo Henríquez. En el prospecto del periódico, en febrero de 1812, el editor señala "La voz de la razón y de la verdad se oirán entre nosotros después del triste, e insufrible silencio de tres siglos. ¡Ah! -exclama- en aquellos siglos de opresión, de barbarie y de tropelías, Sócrates, Platón, Tulio y Seneca hubieran sido arrastrados a las prisiones y los Escritores más celebres de Inglaterra, de Francia y Alemania hubieran perecido sin misericordia entre nosotros. ¡Siglos de infamia y de llanto!" -clama con voz doliente el editor. "La sabiduría y la humanidad llorará siempre sobre vuestra memoria". "Oh"... -implora Camilo Henríquez- "isi la Aurora de Chile pudiese contribuir de

\footnotetext{
5 Idea matriz en el libro de Alfredo Jocelyn Holt sobre la Independencia de Chile.
} 
algún modo a la ilustración de mis compatriotas!” (s/p). Por aquí y por allá el periódico destaca a varios autores de la tradición republicana clásica como Aristóteles, Cicerón y Tito Livio. A partir de estos pensadores y de la idea de comunidad republicana, Camilo Henríquez, Juan Egaña y Manuel de Salas exaltan el rol de la filosofía moral o cívica dentro de la educación pública, sustentando el valor de la razón, y de la libertad (como no dominación), en oposición al despotismo y a la esclavitud. Conciben también a la virtud, al vicio y a la corrupción no como faltas privadas sino como conceptos políticos vinculados a lo público, en la medida en que inciden en el ideal de autogobierno y en el funcionamiento de la república como el sistema político por excelencia (Castillo 38). Los autores del mundo clásico siempre son, por lo tanto, mencionados en la Aurora con valoración positiva, de modo que indirectamente se los va incorporando al canon.

Resulta interesante que explícitamente Camilo Henríquez señale la necesidad de ilustrar al pueblo, pero en español y no en latín, para el director de la Aurora es una "práctica bárbara utilizar el latín en la enseñanza" ("Es preciso" s/p). El latín es la lengua de la Iglesia, de la escolástica, el idioma del contracanon. En el plan de estudios que propone Camilo Henríquez en la Aurora, figuran lenguas modernas como el inglés y el francés, pero no el latín. La ilustración según Camilo Henríquez, "para hacerse popular debe dejar de enseñarse en latín porque este ejercicio no es más que un obstáculo para el conocimiento" ("Es preciso" s/p), debe enseñarse-dice-en el idioma vernáculo. En su discurso de inauguración de la Sociedad Literaria, Lastarria también rescata el legado del idioma castellano, la facundia, la sencillez, la majestad del estilo que está presente en los clásicos españoles, pero no su contenido al que califica de "pobre, rudo y trivial" (10-11). Era la paradoja de tener que usar un idioma heredado de una madre, que súbitamente se transformó -como sostenía Bolívar en su Carta de Jamaica (1815)- en madrastra.

Llama la atención que un miembro de la Iglesia, cuya jerarquía fue más bien contraria a la independencia, sostenga tales posturas e incluso haya sido el adalidad de las mismas. Se trata, sin embargo, de un miembro de lo que la historiografía ha llamado el clero insurgente, sacerdotes como Morelos e Hidalgo en México, curas que actuaron en un contexto en que la Iglesia quedó en una situación ambigua e incluso en algunos lugares, acéfala. La jerarquía, parte importante del clero y el Vaticano, favorecían el Regio Patronato de la Corona, mientras un sector minoritario al comienzo, pero creciente después, 
sostenía que los nuevos Estados eran los legítimos herederos de las potestades que tuvo el Rey de España durante la Colonia ${ }^{6}$.

Dentro de la matriz ilustrada, el republicanismo o humanismo cívico de Camilo Henríquez, Juan Egaña y Manuel de Salas tiene cierta diferencia con el liberalismo de Lastarria y de los jóvenes de 1842, diferencia que se expresa en la prensa: mientras el primer grupo se ocupa de los derechos y las libertades colectivas, el segundo se centra, más bien, en los derechos y en las libertades individuales ${ }^{7}$. De allí que los pensadores y escritos que elijan no sean exactamente los mismos: filósofos, historiadores y pensadores del mundo grecolatino y autores como Montesquieu, Voltaire y Rousseau, en el caso de los primeros, y el liberalismo doctrinario francés y autores como Benjamin Constant, Pradt y Destutt de Tracy pero también Montesquieu y Rousseau, en el caso de Lastarria. Cabe señalar que la primera hornada, en comparación con la de 1842, tuvo una preocupación bastante mayor por los pueblos originarios y sus derechos. Varios de los artículos de la Aurora tocan el tema araucano y el propio Camilo Henríquez escribió utilizando el seudónimo mapuche de Patricio Curiñacu. Los criollos independentistas republicanos se consideraban herederos legítimos de los araucanos. El pensamiento republicano -tal como se infiere del primer escudo nacional (1812) - percibía en el pasado indígena su propia época clásica, concibiendo sí, a los pueblos originarios, en una perspectiva de educación y asimilación. El adjetivo "araucano" llegó a ser un modo de decir "chileno", fue, como señala Mario Góngora, "una glorificación idealizada” (89).

6 Según José Toribio Medina, de los 190 sacerdotes regulares de Santiago solo 22 fueron partidarios de la independencia. El Vaticano solo reconoció la Independencia de Chile en 1840.

7 Gordon Wood denomina "humanismo cívico" al pensamiento de algunos pensadores de la Independencia de Estados Unidos (14). 


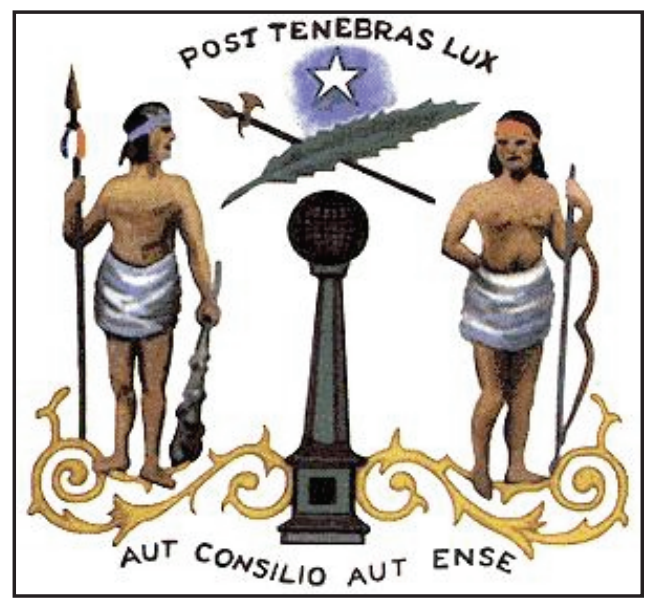

Primer escudo nacional (el lema superior dice "Después de las tinieblas, la luz" y el inferior "O por consejo o por espada")

Juan Egaña publicó en 1819 sus Cartas Pehuenches, obra en que, imitando las Cartas Persas de Montesquieu, puso en boca de dos caciques mapuches la crítica a los vicios y virtudes en los primeros años post independencia. Manuel de Salas, a su vez, fue quien en 1823 colocó una lápida definitiva a la institución de la esclavitud. Tratándose de estos temas, la generación de Lastarria, en cambio, fue más apegada a la dicotomía sarmientina de civilización y barbarie. Cabe señalar, sin embargo, que a pesar de esta diferencia, reconocían y valoraban el hecho de que en 1810 la primera hornada de patriotas haya proclamado a la República como la expresión institucional más adecuada para la nueva nación, en circunstancias de que en Europa Napoleón se estaba coronando, y parte importante de la opinión pública o era monárquica o percibía a esa institución como una de las más favorables para un buen gobierno.

Otros autores que destaca Camilo Henríquez en la Aurora son dos de los historiadores más censurados por el aparato colonial del siglo XVIII español. Se trata de Guillaume Raynal, ex sacerdote jesuita, pensador de la ilustración y la revolución francesa, autor de una Historia Filosófica y política de los establecimientos y del comercio de los europeos con las dos Indias (1770), obra abundante en apasionados ataques al régimen colonial español y en proclamas filosófico-revolucionarias, pero obra menor desde el punto de vista histórico, según Diego Barros Arana (22). Se trata también 
del historiador escocés William Robertson y de su Historia de América, publicada en 1792. Obra muy valorada por la intelligentzia europea de la época por lo bien fundado de su estilo crítico. La saña que en Carlos III y sus ministros provocaban estos dos libros era tal, que mandó escribir dos obras análogas pero por autores españoles y desde el punto de vista de la metrópolis. Probablemente fue el encono de la península hacia estos libros el factor que les abrió el paso al canon de lo que había que leer. El progreso consiste -pensaba Francisco Bilbao- en desespañolizar (El evangelio $)^{8}$. Una vez más comprobamos que las obras que se destacan en la Aurora corresponden a la literatura de ideas en una perspectiva de emancipación, y no a la literatura de ficción, o a las "bellas letras", como se la llamaba entonces. Cabe señalar que la Aurora como periódico no fue un diario en el sentido contemporáneo, en sus 62 números casi no hay crónica ni actualidad, pero sí se instala con ella un espacio público moderno, muy distinto a los espacios de convocatoria de la Colonia: a los pregones, a las campanas de la Iglesia o al púlpito.

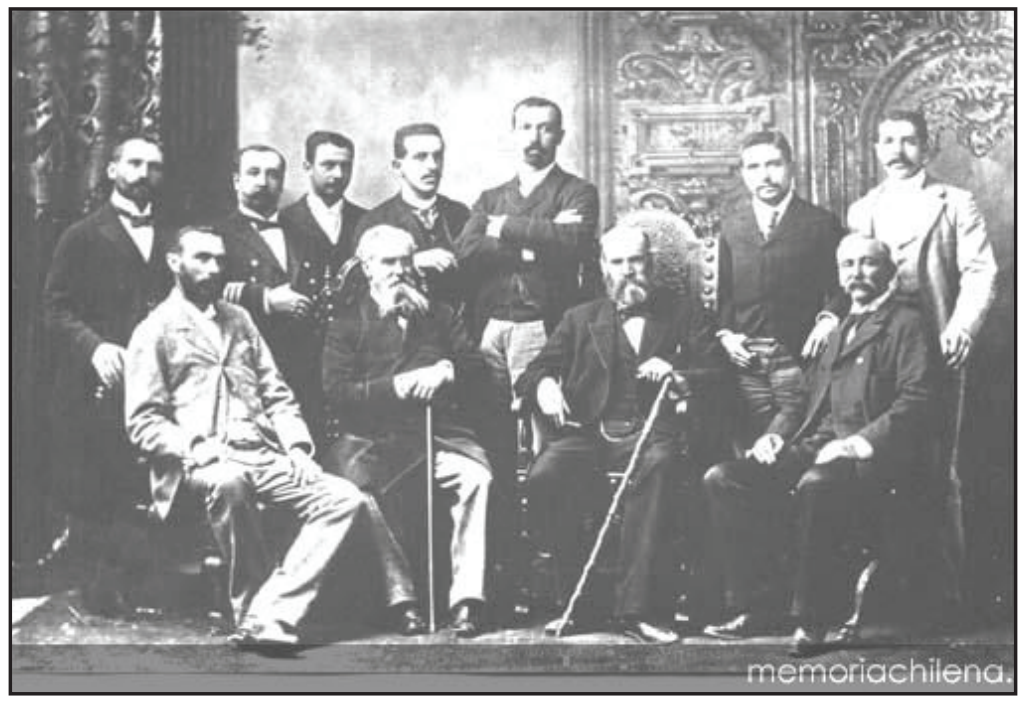

Grupo de intelectuales, siglo XIX. Diego Barros Arana, sentado, tercero de izquierda a derecha

8 Idea matriz de El evangelio americano (1864) de Francisco Bilbao. 
El único libro que se menciona reiteradas veces en la Aurora, y que se vincula a las "bellas letras", y que Camilo Henríquez destaca como imprescindible para el estudio del arte de escribir, es la obra del clérigo escocés Hugo Blair Lecciones sobre la retórica y las bellas letras (publicada en inglés en 1783). Según Henríquez "la obra más profunda y mejor escrita que conocemos sobre esta materia" (Aurora 1) ${ }^{9}$. Hay evidencia de que un compendio de esta obra tuvo un uso docente significativo en el Instituto Nacional de Santiago. La obra de Blair se proponía sustituir en el uso del idioma la retórica artificial y la escolástica por los principios de la razón y del juicio. Blair tenía como parámetros del buen decir y del uso de la lengua y de la composición, la sencillez, el sentido común, la claridad y la exactitud. Su obra recomienda atender más a la sustancia que a los ornatos y a la ostentación, crítica, por lo tanto, al lenguaje y a la sintaxis barroca. En la advertencia del Compendio que circuló en Chile se señala que el aprecio con que se leía la obra de Blair, es prueba de que los "lectores prefieren las ideas sanas a las áridas nomenclaturas, la filosofía luminosa a los sistemas escolásticos y el gusto depurado a la indigesta erudición" (3). Todo lo que atacaba Blair tenía un correlato para la elite ilustrada de las primeras décadas post Independencia. Algunas de las disquisiciones que se realizaron en el seno de la Universidad de San Felipe a fines del siglo XVIII volvían a hacerse presente: por ejemplo, aquella en que un catedrático de esa Universidad argumentó en un tratado que el uso de los vestidos de cola debía imputarse a pecado mortal. Mientras el Rector escribió otro sobre el mismo tema, para demostrar -con argumentos basados en la opinión de los Santos Padres- que el uso de los vestidos de cola no podía imputarse a pecado mortal, pues Santa Rosa los había usado y en la Corte Celestial tenían por Santo Patrono a un tal San Bernardino de Siena que también los había usado, todo esto con un lenguaje enrevesado, pleno de retórica escolástica.

Cabe señalar sin embargo que a Camilo Henríquez y a los ilustrados republicanos les importaba sobre todo la palabra escrita y la cultura letrada, no en función de las "bellas letras", sino en su potencial para el avance de propósitos políticos y culturales, como instrumento para la participación ciudadana en un sistema político y representativo. De ahí también que abogaran insistentemente en la necesidad de "ilustrar y educar al pueblo". La idea de una república, universal en sus principios y abstracta en sus vínculos

9 Estas palabras aparecen en la edición de la Aurora del 25 junio 1812. 
-vía la constitución y las leyes- solo era posible a través de la escritura y de una cultura letrada (Serrano y Jaksic, "El poder"). Quién sí se preocupó desde su llegada a Chile de las bellas letras, fue Andrés Bello. Recién llegado al país, en el Araucano, Bello comentó y propuso modelos poéticos afines a la poesía cívica de corte neoclásico, e integró también al canon de la literatura chilena nada menos que a la Araucana de Ercilla, leyéndola -en artículo de 1841- como una épica fundante de la nación, como "nuestra Eneida" (34).

En la generación de 1810, además de la literatura de ideas, que el editor de la Aurora engloba en la categoría de filosofía civil, se mencionan también otros "libros útiles", libros que merecen ser importados y leídos. Según Camilo Henríquez "uno de los muchos modos con que el comercio promueve y favorece la literatura -repárese en el uso del concepto de literatura- es la introducción de libros científicos y generalmente útiles. Harán pues un gran servicio a la patria -dice- los comerciantes que hagan venir tantas obras preciosas" (Aurora $\mathrm{s} / \mathrm{p})^{10}$. También señala la necesidad de importar diccionarios y gramáticas del idioma inglés: recordemos, que para Camilo Henríquez más que la Francia de Napoleón, era Estados Unidos el modelo republicano por excelencia, en sus palabras: de "un país industrioso y culto" en el que "todos leen, todos piensan y todos hablan con libertad" (Hernández 73), (valoración curiosa considerando que en varios Estados de esa nación todavía operaba la esclavitud y la población negra estaba excluida de los logros del país). En la prefiguración del canon de libros que hay que leer, Camilo Henríquez asume, entonces, la voz de una conciencia nacional, no se trata de un canon personal, sino de un canon que debe ser accesible, que debe ser parte del canon educativo y, por lo tanto, un canon que debiera ser oficial en la perspectiva de preparar un "porvenir feliz" para la nueva nación chilena.

Otra vía de constitución del canon en los años posteriores a la Independencia son las traducciones. Traducir implica una elección y un ejercicio profundo de lectura intercultural. Ante la ausencia de crítica, el proceso de traducción era un mecanismo más o menos directo para ampliar el canon. La primera publicación de una obra traducida data de 1820 , se trata de $E l$ Diccionario portátil filosófico-político-moral. Obra útil y provechosa a las personas de cualesquiera opinión política que aspiren a figurar en el mundo por principios de una educación a la derniere, obra que fue publicada-como

10 Estas palabras aparecen en la Aurora del 19 de marzo de 1812. 
dice el facsimilar- en la Imprenta de los ciudadanos Valles y Vilugron. Se trata de una obrita de pocas páginas, de autor anónimo, que se firma con el seudónimo de Barón de Bribonet, texto inspirado en el Diccionario filosófico portátil (1764) de Voltaire. El texto está precedido de una "Advertencia (s) del traductor, con honores de prólogo", en que el autor anónimo señala "Téngola por producción original, que se ha querido disfrazar con las apariencias de una traducción" ( $\mathrm{s} / \mathrm{p})$. Traducción o seudotraducción, lo importante es que se basa en la obra de Voltaire, autor que no solo fue censurado y prohibido durante la Colonia, sino también en el interregno del ministro de Portales, autor que fue un modelo para los ilustrados chilenos de cuño republicano y liberal. Antes, en 1828, durante el gobierno del general Francisco Antonio Pinto -a quien un historiador llamó filósofo con espada ${ }^{11}$ - en la entrega de premios del Instituto Nacional, el presidente Pinto obsequió a un alumno destacado las Obras Completas de Voltaire.

En cuanto a traducciones, el propio Camilo Henríquez tradujo del inglés un discurso del poeta John Milton sobre la libertad de prensa, pronunciado en el parlamento de Inglaterra, texto que publicó en la Aurora. Otra traducción que se publicó en 1825 fue el Compendio de las lecciones sobre la retórica y las bellas letras, de Hugo Blair, al que ya nos hemos referido. Otro título fue La conciencia de un niño, obra traducida del francés por Domingo Faustino Sarmiento y publicada en 1844 para el uso -como indica la portadilla-de las escuelas primarias". Solo en 1844 , se traducen y publican obras de ficción propiamente tal: una novela de Balzac y dos de Eugenio Sue (La tremielga, El judio errante y Los misterios de París). En definitiva, entre 1820 y1845, la mayoría de las obras traducidas corresponden a lo que llamamos literatura de ideas y solo unas pocas, muy pocas, a lo que se consideraba entonces "bellas letras".

En Camilo Henríquez y la Aurora se encuentran, como hemos señalado latamente, diversas respuestas a la pregunta ¿qué leer?, respuestas que responden a las preconcepciones ideológico políticas de una mentalidad ilustrada de cuño republicano, supuestos que son también en gran medida compartidos por la generación de 1842. De allí que hablemos de prácticas lectoras y de una comunidad de interpretación comunes. El canon de la literatura de la Independencia que responde a la pregunta de ¿qué leer?, está conformado, entonces, para esta comunidad, por algunos de los autores más

11 Se trata del historiador y ensayista Alberto Edwards. 
destacados de la antigüedad clásica, por pensadores ilustrados como Voltaire, Rousseau y Montesquieu, entre otros, por autores del liberalismo doctrinario francés, también por autores del contra-canon de la España colonial y por "libros útiles", sean científicos o diccionarios.

La generación de 1810 no se hace sin embargo la pregunta de ¿qué escribir?; de hecho, en un número de la Aurora, Camilo Henríquez se interroga “¿De qué sirve escribir si no hay quien lea?” (4) ${ }^{12}$. Una situación muy distinta ocurre con los miembros de la generación de 1842. Comparten el uso enciclopédico y no restrictivo del concepto de literatura, pero también les preocupa y mucho el destino de las "bellas letras". Un segmento significativo del discurso de Lastarria en la inauguración de la Sociedad Literaria está destinado a reflexionar sobre las características que debe tener la literatura de imaginación en Chile y sobre todo la necesidad de crear una literatura propia que no sea una simple imitación del modelo europeo. Reconoce y valora la literatura francesa: "De San Petersburgo a Cádiz, dice, no se leen más que libros franceses, ellos inspiran el mundo". "Debo deciros, pues, que leáis los escritos de los autores franceses de más nota en el día-se refiere sin duda al romanticismo social; pero añade una advertencia "no para que los copiéis y trasladéis sin tino a nuestras obras, sino para que aprendáis de ellos a pensar, para que os empapéis en ese colorido filosófico que caracteriza a su literatura" (10-11). Lastarria propicia una literatura que, rescatando del legado español solo el don de la lengua, se independice frente a los valores hispánicos, una literatura que se inspire en lo propio, en la historia patria, en las peculiaridades sociales, en el paisaje y en la naturaleza americana, una literatura que sea -dice- "la expresión auténtica de nuestra nacionalidad" (10-11). Propone también una literatura edificante: escribir para el pueblo, combatir los vicios y realzar las virtudes. Los miembros de la Sociedad Literaria se sienten, entonces, responsables de una tarea tanto o más importante que la de los padres de la patria; se trata de completar la independencia política con la independencia cultural; de la fundación de la nación y, simultáneamente, de la fundación de su literatura.

Hasta aquí nos hemos movido en el plano de las ideas, del deber ser, en el ámbito de un constructivismo utópico de cuño ilustrado. ¿Pero qué pasaba en la realidad real con los libros y la lectura? ¿Con la educación? ¿Con la república de facto? Fuente importante son los testimonios de los viajeros, de

12 Estas palabras aparecen en la Aurora del 7 de mayo de 1812. 
personajes como John Miers, el botánico e ingeniero inglés que visitó Chile e Hispanoamérica entre 1818 y 1819, o de Alexander Caldcleuhg, que estuvo en el país en los mismos años que Miers, o de María Graham, la escritora y viajera británica que llegó a Valparaíso en 1822.

John Miers, refiriéndose al conocimiento y manejo del español en la sociedad chilena de la época, observa que "el idioma practicado usualmente entre los chilenos está lejos del límpido castellano", luego de señalar que el idioma español es uno de los de mayor riqueza léxica y expresiva entre las lenguas modernas, Miers nos dice que "el de los chilenos" en cambio "...es pobre y ramplón, agudizado por una intolerable pronunciación nasal y una carencia de vocabulario escasamente suficiente para expresar sus limitadas ideas". "Algunos con quienes me he reunido -agrega luego-no tienen remota idea de geografía, o incluso de la topografía de su propio país; son ignorantes sobre la ubicación relativa de los diferentes Estados de América hispana, como lo son también respecto a otras partes del mundo. Muchos, entre las personas más cultas de las clases acomodadas, me han inquirido si Inglaterra está en Londres, o si Londres en Inglaterra, o sí la India cerca de ella, y otras preguntas similares. He encontrado la misma ignorancia entre letrados y doctores sabios de la ley. Puede decirse-concluye-que la formación cultural (humanista) existe escasamente entre ellos" (Cit. en Piwonka 180).

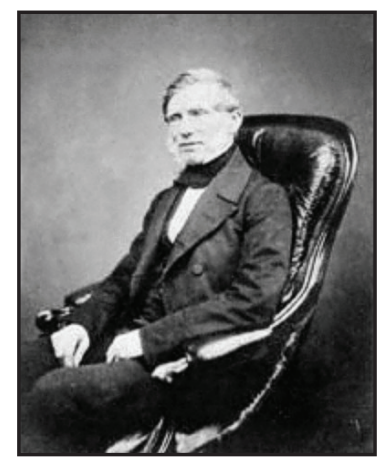

John Miers

Respecto a la educación, le llama poderosamente la atención que al mejor colegio de Santiago, con capacidad para más de 300, solo llegan 120 alumnos. Se refiere a la Academia San Luis, heredera del Convictorio Carolingio de los jesuitas, a la que acudían los hijos de los hacendados y de los comerciantes más poderosos. Refiriéndose al Instituto Nacional de Santiago, señala que 
allí se enseña gramática, latín y aritmética; se inician en los principios de la teología y la filosofía; la aritmética se lleva escasamente más allá de la instrucción en las cuatro reglas elementales; y la filosofía enseñada...no es más que una serie de dogmas ininteligibles e inútiles" (Cit. en Piwonka 181).

Con respecto a la lectura y los libros, su testimonio es lapidario: "El egoísmo y petulancia de los chilenos - dice-es proporcional a su ignorancia", "es un orgullo no requerir del conocimiento de libros; de hecho tienen escasamente algunos y en ocasiones no pueden soportar el problema de leer aquellos que poseen". Se está refiriendo a la elite letrada y a los patriarcas de la oligarquía local. "Recuerdo -agrega- que el Presidente del Senado, un hombre respetado por sus compatriotas", una voz autorizada y escuchada, "alardeaba de no haber examinado un libro durante 30 años, y otro funcionario principal del Gobierno, quien se jacta de ser un hombre culto y erudito" con "inmodestia similar" insinúa que "para él el conocimiento extraído de los libros" resulta "innecesario". "Por consiguiente" concluye "los libros son entre ellos muy escasos" (Cit. en Piwonka 181).

Como extranjero que traía libros entre sus pertenencias, su testimonio con respecto a la censura es elocuente: "ningún libro era permitido sin estar visado por algún funcionario de la aduana, ni inclusive enviarse de Valparaíso a Santiago sin el examen más estricto, con el propósito de prevenir la introducción de cualquier trabajo que tendiese al... conocimiento herético... se ordenó que cada libro ofensivo fuera destruido. Estas prohibiciones, señala finalmente, solo afectan a los extranjeros, puesto que, como los chilenos no tienen ningún placer en leer, no vale la pena importar libros, ya que no producen utilidades" (Cit. en Piwonka 181-182).

Podría pensarse que se trata -en el caso del ingeniero y botánico inglés- de un testimonio sesgado, debido a que fracasó en sus proyectos mineros. Hay, sin embargo, otros testimonios que corroboran lo señalado por Miers. La viajera y escritora inglesa María Graham donó a la Biblioteca Nacional en 1823, cuando abandonó el país, una cantidad importante de libros, que quedaron apilados y solo muchos años después fueron incorporados a la colección de la Biblioteca. La donante ni siquiera recibió una nota de agradecimiento (Cit. en Piwonka 182). Alexander Caldcleugh, viajero inglés que estuvo en Chile en los mismos años que Miers, aunque menciona algunas bibliotecas particulares de importancia, como la de Manuel de Salas, ratifica -con tintas más moderadas- algunas de las observaciones de Miers. Andrés Bello, en 1829, recién llegado al país, en carta que da cuenta de sus 
primeras impresiones sobre la vida cultural expresa "cierto desencanto", "la poesía -dice- no tiene aquí muchos admiradores" y "El Mercurio chileno", periódico que califica de excelente, "no tiene quizás sesenta lectores en todo el territorio de la República" (Cit. en Mellafe s/p.) Vicuña Mackenna se quejó más de una vez en la prensa debido a que los libros se vendían en Santiago en almacenes, entre papas, sebo, géneros y aceite, lo que era una afrenta para una mentalidad ilustrada.

Salta a la vista, a partir de estos testimonios, la disparidad entre, por una parte, la situación de la cultura letrada en los años posteriores a la Independencia, y por otra, el ánimo y las preconcepciones de la comunidad de lectores ilustrados en sus alcances utópicos y constructivistas, con propuestas de un canon para la nueva nación. Se hace visible la conjunción de un pensamiento moderno con una sociedad arcaica, el desfase que media entre el proyecto de modernización republicano y liberal y la realidad cultural existente. Se trata de una disociación que abre un viejo tema de la elite en América Latina, el de la pugna entre los hombres montados a caballo en ideas y los hombres montados a caballo en la realidad. Contienda que, como ha señalado Elias Palti no se trata de la oposición entre ideas y realidad, sino entre dos discursos opuestos o entre visiones diversas de la realidad (22).

Desde antes de la Independencia y durante todo el siglo XIX, esta polaridad fue abordada por políticos e intelectuales hispanoamericanos, $\mathrm{y}$ lo fue básicamente en torno a tres órdenes de argumentos que se hicieron presentes en la prensa, en la correspondencia y en la historiografía de la época: la postura autoritaria, que se opone a todo cambio que altere el statu quo y las condiciones orgánicas de la vida socio económica (a las que, por ende, congela); postura que expresa bien una carta que escribió Diego Portales desde Lima a su socio José Manuel Cea, en 1822: "La democracia que tanto pregonan los ilusos, es -le decía- un absurdo en países como los americanos, llenos de vicios y donde los ciudadanos carecen de toda virtud... para establecer una verdadera república". Señala luego el tipo de gobierno que hay que adoptar: "un gobierno fuerte, centralizador, cuyos hombres sean verdaderos modelos de virtud y patriotismo y así enderezar a los ciudadanos por el camino del orden..." (145). La segunda es una postura de mediación y de posibilismo, que busca establecer puentes y regular la temperatura ideológica de las ideas políticas modernas: por ejemplo, Simón Bolívar en su Carta de Jamaica, de 1815, aboga persuasivamente no por la adopción ipso facto de una forma de gobierno acorde a las ideas modernas, ni por una 
que petrifique lo existente, sino por la que fuese más posible de acuerdo a la acomodación de los ideales republicanos con la realidad geográfica, social y política de ese momento. También Andrés Bello ejerció una mediación de esta índole con respecto a las ideas y al quehacer intelectual de la generación de 1842, permitiendo la continuidad del pensamiento de los jóvenes liberales en un contexto portaliano que les era adverso. En su magisterio intelectual, Bello colaboró a borrar las diferencias causadas por la Independencia y por las sucesivas confrontaciones entre liberales y conservadores, al comienzo y al final del gobierno de Montt ${ }^{13}$. La tercera postura es la de aquellos que se instalan de modo intransigente en las ideas y doctrinas modernas, postura que encarna José Victorino Lastarria, cuando fustiga las concesiones doctrinarias, la política que él llama "de la madre rusa", de esa madre que sorprendida en las estepas por una manada de lobos fue arrojando a sus pequeños, uno tras otro, tratando inútilmente de saciar a los lobos, hasta que cayó ella misma devorada: "Esa es la política -decía- de los sacrificios inútiles... No, no debemos abandonar nunca la lógica y la integridad de las doctrinas" (Cit. en Orrego Luco 12). En definitiva: ¡Que se salve la libertad... aunque perezca el mundo!

Si bien las bellas letras no son un mero reflejo de las alternativas del pensamiento, la independencia de la literatura nacional se irá construyendo a la par de esta dialéctica entre las ideas y la sociedad. Desde las fricciones, flujos e intersticios entre lo moderno y lo arcaico, y de los sustratos sociales e ideológicos que nutren y sustentan estas refriegas, se irá conformando el imaginario literario de Alberto Blest Gana, la figura más destacada de la literatura chilena del siglo XIX. Piénsese, por ejemplo, en su obra Martín Rivas (1862), en las figuras de Don Dámaso Encina (que representa el sustrato convencional hispano católico), en el personaje Martín Rivas (que es la figura de la mediación y del posibilismo en la perspectiva de la construcción de la nación), y en Rafael San Luis (que encarna la voz de la intransigencia liberal y romántica).

13 Aunque Mizón no menciona a Bello, sugiere en su libro que esta borradura fue funcional a los intereses de la clase dirigente. 


\section{BILIOGRAFÍA}

Agamben, Giorgio. Infancia e historia. Buenos Aires: Adriana Hidalgo, 2004.

Barros Arana, Diego. Historia General de Chile. Tomo VII. Santiago: Editorial Universitaria, 2000 .

Bello, Andrés. Obras Completas. Caracas: Ministerio de Educación, 1951.

Bilbao, Francisco. El evangelio americano. Edición facsimilar de consulta virtual de 1864. Memoria chilena http://www.memoriachilena.cl/temas/dest.asp?id=bilbaoevangelio

Blair, Hugo. Compendio de las lecciones sobre la retórica y bellas letras de Hugo Blair. Trad. José Luis Munarriz. Madrid: Edición Facsimilar, 1815. Biblioteca Virtual Miguel de Cervantes http://www.cervantesvirtual.com/FichaObra.html?Ref=31562\&portal=42

Bribonet, Barón de. El Diccionario portátil filosófico-politico-moral. Obra útil y provechosa a las personas de cualesquiera opinión política que aspiren a figurar en el mundo por principios de una educación a la derniere. S/1: Imprenta de los ciudadanos Valles y Vilugron, 1820.

Castillo, Vasco. "Camilo Henríquez: del amor a la patria, a la libertad política. Una lectura de su pensamiento político en clave republicana”. Revista Mapocho 54 (2003): 33-52.

Chartier, Roger. El mundo como representación. Estudios sobre historia cultural. Barcelona: Gedisa, 1992.

El orden de los libros. Lectores, autores, bibliotecas en Europa entre los siglos XIV y XVIII. Barcelona: Gedisa, 1994.

Góngora, Mario. Estudios de historia de las ideas y de la historia. Valparaíso: Universitarias de Valparaíso, 1980.

Henríquez, Camilo. "De la influencia de los escritos luminosos sobre la suerte de la humanidad". La Aurora (7 de mayo, 1812).

"Es preciso ilustrar al pueblo". La Aurora (7 de mayo, 1812).

"Prospecto". Aurora 1 (13 de febrero, 1812).

Aurora (25 de junio, 1812).

Aurora 6 (19 de marzo, 1812).

Aurora (7 de mayo, 1812).

Hernández, Roberto. Camilo Henríquez y la publicación de la Aurora en Chile. Valparaíso: S/e, 1930.

Jocelyn-Holt, Alfredo. La Independencia de Chile. Tradición y mito. Santiago: De Bolsillo, 2009.

Lastarria, José Victorino. Discurso de Incorporación a una Sociedad Literaria. Edición facsimilar, 1842.

Mannheim, Karl. Ideología y utopía. Madrid: Fondo de Cultura Económica España, 1997.

Martínez, Melchor. Memoria histórica sobre la Revolución en Chile. Valparaíso: S/e, 1847.

Medina, J.T. Biblioteca Chilena de Traductores (1820-1924). Edición corregida y aumentada con estudio preliminar de Gertrudis Payas. Santiago: DIBAM, 2007. 
Mellafe, Rolando. "Carta del 20 de agosto de 1829 a José Fernández Madrid”. Historia de la Universidad de Chile. Santiago: U. de Chile, 1992.

Mizón, Luis. Claudio Gay y la formación de la identidad cultural chilena. Santiago de Chile: Universitaria, 2001.

Orrego Luco, Augusto. "Don Victorino Lastarria, impresiones y recuerdos". Revista Chilena 1(1917): 10-22.

Palma, Ricardo. Anales de la Inquisición de Lima. 1863. Lima: Reproducción digital de edición facsimilar (tipografía de Aurelio Alfaro), 1997.

Palti, Elías. El tiempo de la política. Buenos Aires: Siglo XXI, 2007.

Piwonka, Gonzalo. "John Miers (1789-1879), viajero crítico de los chilenos en los comienzos de la República”. Cuadernos de Historia 30 (marzo 2009): 149-191.

Poblete, Juan. Literatura chilena del siglo XIX: entre públicos lectores y figuras autorales. Santiago: Cuarto Propio, 2003.

Portales, Diego. Ideas y confesiones de Portales. Santiago: Editorial del Pacífico, 1954.

Savater, Fernando. Diccionario Filosófico. Madrid: Planeta, 1999.

Serrano, Sol. "Rol histórico de los intelectuales en Chile". Proposiciones 24 (1994): 164169.

Serrano, Sol e Iván Jaksic. "El poder de las palabras: la Iglesia y el Estado Liberal ante la difusión de la escritura en el Chile del Siglo XIX". Historia. Vol.33. Santiago: Pontificia Universidad Católica, 2000. 435-460.

Wood, Gordon. The creation of the American Republic. USA: University of North Carolina Press, 1969. 